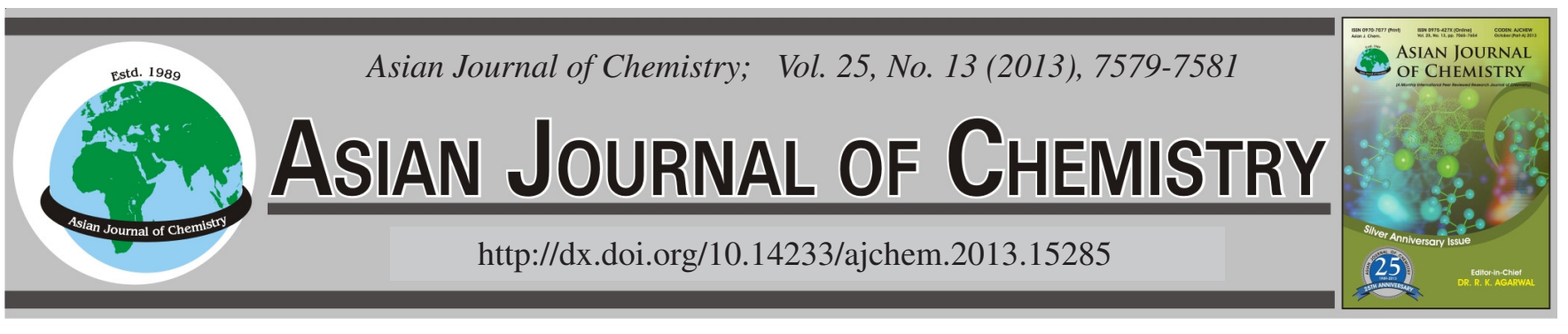

\title{
Preparation and Surface Modification ZnO Nano-Powder with Antifriction Properties
}

\author{
FENGHUA JIANG ${ }^{1,2, *}$
}

${ }^{1}$ School of Materials Science and Engineering, University of Jinan, Jinan 250022, P.R. China

${ }^{2}$ ShanDong Provincial Key Laboratory of Preparation and Measurement of Building Materials, Jinan 250022, P.R. China

*Corresponding author: Tel: +86 531 88525387; E-mail: mse_jiangfh@ujn.edu.cn

(Received: 6 February 2013;

Accepted: 1 July 2013)

AJC-13756

In this work, the surface modified $\mathrm{ZnO}$ nano-powder is prepared by the method of the combination of direct precipitation and in situ surface modification. The prepared samples are characterized by the means of laser particle size analysis, scanning electron microscopy, $\mathrm{X}$-ray diffraction analysis and Fourier transform infrared spectroscopy. In the tribological test, by adding the surface modified ZnO nanopowder, the friction coefficient and the wear scar diameter of lubricants can be significantly reduced. The powder plays a role in antifriction.

Key Words: Precipitation method, In situ surface modification, ZnO nano-powder, Antifriction.

\section{INTRODUCTION}

The friction and wear of the problems commonly were existed in any machine. Especially, the large-scale, precision machinery and equipment, it's parts in the lubrication and antiwear performance requirements improve, this will force us to study new additive of lubricating oil ${ }^{1}$. In recent years, research of nanometer materials in the lubrication antifriction and antiwear were rapidly developed. Adding lubricating oil additives have been used in ships, tanks and armored vehicles to improve engine performance and reduce the equipment between parts wear and prolong the service life of the mechanical equipment in the United States and Russia and other countries ${ }^{2}$. Researchers were working on antiwear and antifriction mechanism of lubricating oil with nanometer additives ${ }^{3}$. Yunhui ${ }^{4}$ developed nano tin lubricant, in short time internal friction surface get thicker coating, rise to wear self repair function. Guichang et al. ${ }^{5}$ developed styrene and methacrylic acid, titanium dioxide nanometer microspheres, which has good tribological properties. The domestic research institutions successively in nanometer lubricating oil additive on the research and application and in the military equipment and aerospace and other fields have achieved good effect ${ }^{6}$.

\section{EXPERIMENTAL}

Preparation of $\mathrm{ZnO}$ nano-powder: Firstly, a certain amount of silane coupling agent KH560 dissolved into alcohol solution for hydrolysis (solution A). And a certain amount of polyvinyl dissolved into deionized water and heated in the muffle furnace to $90{ }^{\circ} \mathrm{C}$ until the solution became colourless clear (solution B). To prepare $\mathrm{Zn}\left(\mathrm{NO}_{3}\right)_{2}$ solution, a certain amount of $\mathrm{Zn}\left(\mathrm{NO}_{3}\right)_{2}$ was weighed and dissolved in deionized water and heated on a magnetic stirrer at $65^{\circ} \mathrm{C}$ until the solution became colourless (solution $\mathrm{C}$ ). The polyvinyl alcohol solution was selected as a dispersant. After solution B was put into solution $\mathrm{C}$ for full dispersion, then solution $\mathrm{A}$ was put into and was heated on a magnetic stirrer at $60^{\circ} \mathrm{C}$. At the same time, the solution was slowly dropped into ammonia water, was controlled reaction temperature $60^{\circ} \mathrm{C}$ and the $\mathrm{pH}$ of the solution was $c a$. 8, till no precipitation existed in the solution. After washing by deionized water until no $\mathrm{NO}_{3}{ }^{-}$, the precipitate was placed in a vacuum drying box for drying. The dried precipitate was removed by grinding for differential thermal analysis. According to the results of DTA, the calcining temperature of nano-powder was determined.

Characterizations of ZnO Nano-powder: The crystal form of $\mathrm{ZnO}$ nano-powder was analyzed by X-ray diffraction analysis. The formation of covalent bands was testified by Fourier Transform Infrared Spectroscopy (FTIR). The diameters of $\mathrm{ZnO}$ nano-powder was analyzed by the means of laser particle size analysis (PSA). Through scanning electron microscopy (SEM) was investigated the dispensability of $\mathrm{ZnO}$ nano-powder. Finally, the antifriction properties of $\mathrm{ZnO}$ nanopowder as additives into lubricating oil were tested by the fourball wear test.

\section{Friction test}

Preparation of samples: The lubricating oil was tested as a sample A. The sample B was prepared that $\mathrm{ZnO}$ nanopowder was added into lubricating oil with mass concentration 
$0.05 \%$. The oil solution was dispersed in the ultrasonic for $2 \mathrm{~h}$. After $\mathrm{ZnO}$ nano-powder was homogenously dispersed in the lubricating oil, the oil solution was kept at room temperature for 3 day before friction tests. The same method, the sample $\mathrm{C}$, the sample D and the sample E were prepared that $\mathrm{ZnO}$ nano-powder was Added into lubricating oil with different mass concentration $0.1,0.5$ and $1 \%$.

Four-ball wear test: This test method for determination of the coefficient of friction of lubricants using the four-ball wear test machine (ANSI/ASTM D5183-2005). In the friction process, test parameters were set as follows, the temperature for: $75^{\circ} \mathrm{C}$, the load for: $147 \mathrm{n}$, the speed for: $1450 \mathrm{rpm}$, the test time for $0.5 \mathrm{~h}$. The samples were four-ball test, the computer automatic recording data.

\section{RESULTS AND DISCUSSION}

DTA-TG analysis: Fig. 1 is the DTA-TG results of synthesized $\mathrm{ZnO}$ nano-powder in the range of room temperature to $800{ }^{\circ} \mathrm{C}$. The weight loss reached over $82.5 \%$ before $400{ }^{\circ} \mathrm{C}$, indicating the $\mathrm{ZnO}$ nano-powder mainly converted to oxides at $400{ }^{\circ} \mathrm{C}$ precipitate and the mass loss was mainly caused by the decomposition of the evaporation of the adsorbed water in the $\mathrm{Zn}(\mathrm{OH})_{2}$. In the DTA curve, there was a endothermic peak that appeared at $\mathrm{ca} .200{ }^{\circ} \mathrm{C}$ was due to the loss of adsorbed water and crystallization water in the precursor.

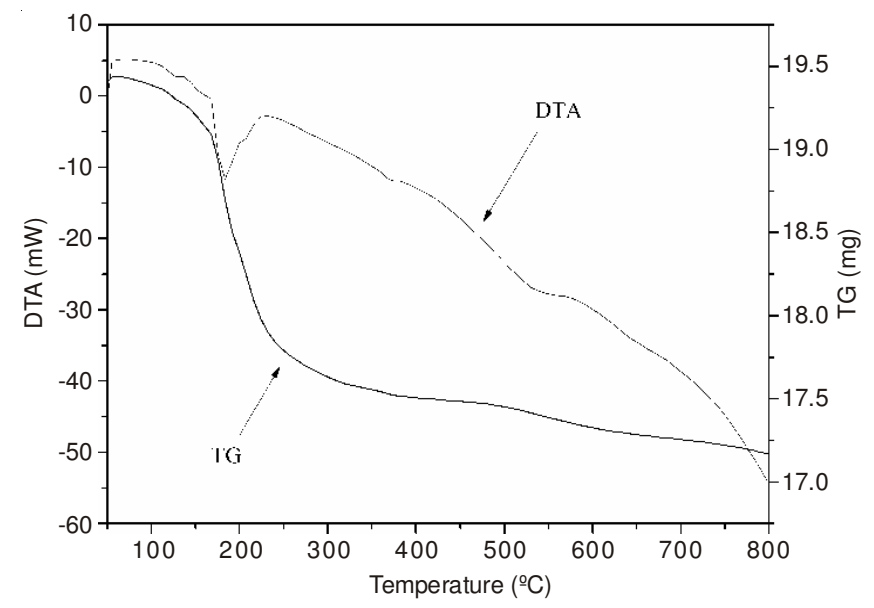

Fig. 1. DTA curve and TG curve of synthesized $\mathrm{ZnO}$ nano- powder

XRD analysis: The XRD pattern of synthesized nanopowder after surface modification and calcinations was illustrated in Fig. 2. It can be indexed as orthorhombic crystalline structure with the diffraction peaks $\mathrm{d} 1=2.48 \AA$, d $2=2.81 \AA$ and $\mathrm{d} 3=2.60 \AA$, which is agreeable with the standard diffraction chart of $\mathrm{ZnO}$ in JCPDS-65-3411 indicating the $\mathrm{ZnO}$ phase has good crystallinity and there is no impurities.

FTIR analysis: Fig. 3 shows FTIR spectra of $\mathrm{ZnO}$ nanopowder (a) and $\mathrm{ZnO}$ nano-powder modified with KH-560 (b). For the spectra (b), the pack at 2908 and $2908 \mathrm{~cm}^{-1}$ attributed to hydroxyl $(-\mathrm{OH})$ stretching vibration were observed. The absorption peak at 1632 and $1039 \mathrm{~cm}^{-1}$ corresponds to $(-\mathrm{C}=\mathrm{C}-$ ). Since peaks in spectra of $\mathrm{ZnO}$ nano powder (a) were not appeared, $\mathrm{ZnO}$ nano-powder surface modified with $\mathrm{KH}-560$ have $(-\mathrm{OH})$ and $(-\mathrm{C}=\mathrm{C}-)$.

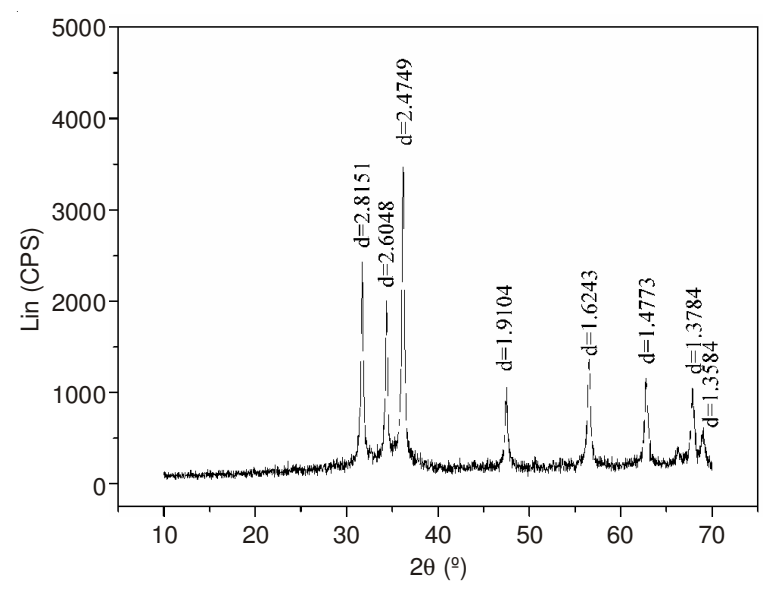

Fig. 2. XRD pattern of $\mathrm{ZnO}$ nano-powder after calcination

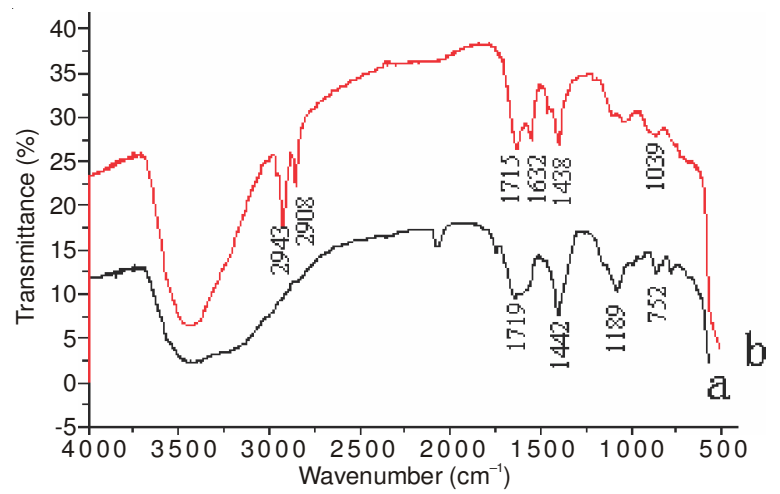

Fig. 3. FTIR spectra of $\mathrm{ZnO}$ nano-powder (a) without surface modification (b) with surface modification

Grading analysis: Fig. 4 shows the grading analysis result of synthesized $\mathrm{ZnO}$ nano-powder. It can be seen that the particle size of the $\mathrm{ZnO}$ samples agreed with normal distribution. The minimum particle diameter was less $40 \mathrm{~nm}$ and the average particle diameter was $c a .90 \mathrm{~nm}$. The median diameter of particles was approximately $76 \mathrm{~nm}$.

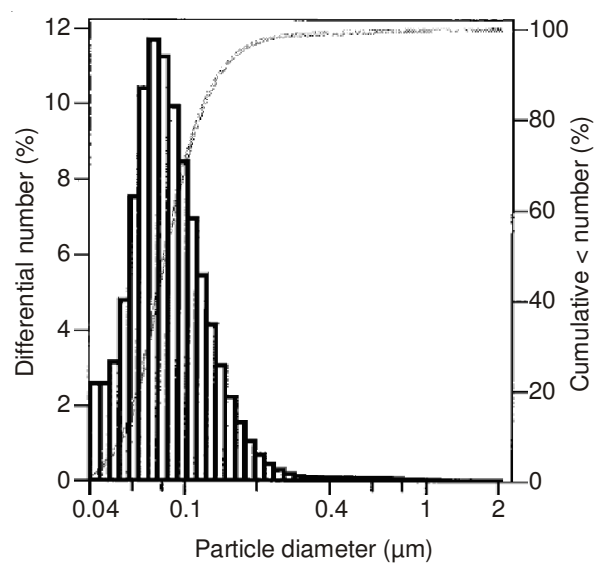

Fig. 4. Grading analysis result of synthesized $\mathrm{ZnO}$ nano-powder

Table-1 lists the size distribution of $\mathrm{ZnO}$ nano-powder. It can be seen that the particles less 53, 61 and 76 nmwere nearly 10, 25 and $50 \%$ in the $\mathrm{ZnO}$ nano-powder, respectively. The particle less $109 \mathrm{~nm}$ was nearly $75 \%$, indicating the size distribution of particle was well and the synthesized powder was nano size. 


\begin{tabular}{ccccc}
\hline \multicolumn{5}{c}{ TABLE-1 } \\
GRADING ANALYSIS TABLE OF \\
SYNTHESIZED ZnO NANO-POWDER \\
\hline$>10 \%$ & $>25 \%$ & $>50 \%$ & $>75 \%$ & $>90 \%$ \\
\hline $0.053 \mu \mathrm{m}$ & $0.061 \mu \mathrm{m}$ & $0.076 \mu \mathrm{m}$ & $0.109 \mu \mathrm{m}$ & $0.131 \mu \mathrm{m}$ \\
\hline
\end{tabular}

SEM analysis: SEM images (Fig. 5) shows of ZnO nanopowder. It can be seen that the most of the particles of calcined $\mathrm{ZnO}$ powder was relatively small and distributed well. The morphology of particle was regular and nearly spherical. Only a small part of particles agglomerated.
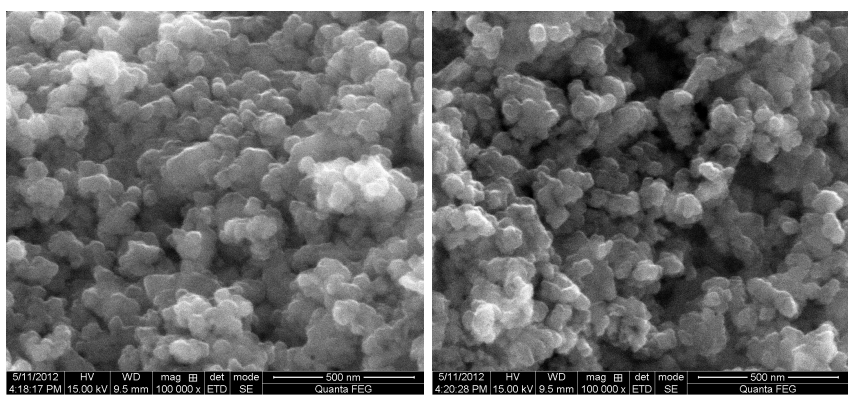

Fig. 5. SEM images of $\mathrm{ZnO}$ nano-powder

Friction tests analysis: Fig. 6 shows wear scars of samples by four-ball wear tests. The antiwear properties were changed because modified $\mathrm{ZnO}$ nano-powder joined into lubricating oil. The wear scars diameter of the sample D (concentration $0.5 \%$ ) by four-ball wear tests is $490.25 \mu \mathrm{m}$ and sample D's is $632.42 \mu \mathrm{m}$. Fig. 7 showed friction coefficients changes of samples by four-ball wear tests. Friction coefficients of samples decreased with concentrations of $\mathrm{ZnO}$ increased until the concentration was $0.5 \%$ and concentrations of $\mathrm{ZnO}$ increased friction coefficients of samples increased. Table- 2 shows wear scars diameters and average friction coefficient by four ball wear tests. At $0.5 \%$ concentrations of $\mathrm{ZnO}$, the friction coefficient of sample decreased to minimum value, the sample D antifriction the best performance.

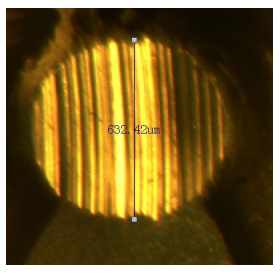

(a) Sample A

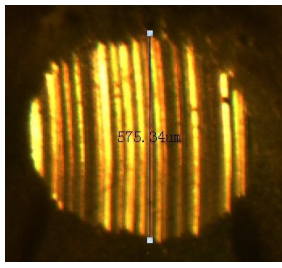

(b) Sample B

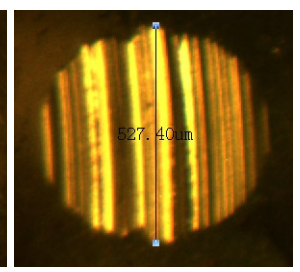

(c) Sample C

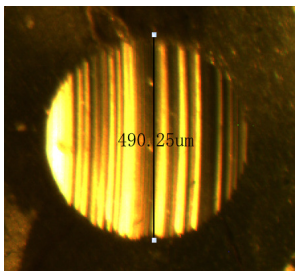

(d) Sample D

Fig. 6. Wear

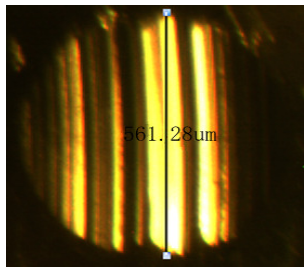

(e) Sample E

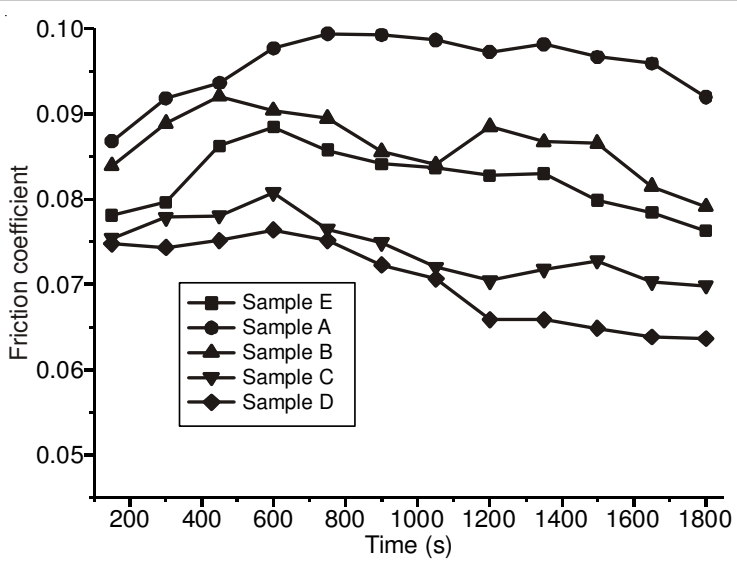

Fig. 7. Friction coefficients of samples by four-ball wear tests

\begin{tabular}{ccc} 
& \multicolumn{2}{c}{ TABLE-2 } \\
& RESULTS OF FOUR-BALL WEAR TESTS \\
\hline No & Wear scar diameter $(\mu \mathrm{m})$ & Friction coefficients \\
\hline Sample A & 632.42 & 0.096 \\
Sample B & 575.43 & 0.087 \\
Sample C & 527.40 & 0.076 \\
Sample D & 490.25 & 0.071 \\
Sample E & 561.28 & 0.083
\end{tabular}

\section{Conclusion}

- ZnO nano-powder was synthesized by direct precipitation and in situ surface modification. The minimum size of particle was less than $40 \mathrm{~nm}$ and the average diameter of particle of was $c a .90 \mathrm{~nm}$. The median diameter of spherical particles was $c a .76 \mathrm{~nm}$.

- Hydrolysis of silane coupling agent (KH-560) can well $\mathrm{ZnO}$ nano-powder surface modified with $(-\mathrm{OH})$ and $(-\mathrm{C}=\mathrm{C}-)$. After $\mathrm{ZnO}$ nano-powder was achieved the effect of surface modification, it was well dispersion and stability in the lubricating oil.

- Through four-ball wear tests were concluded that $\mathrm{ZnO}$ nano-powder additive to put into lubricating oil were played a better antiwear effect, the friction coefficient and the wear scar diameter can be significantly reduced. When the $\mathrm{ZnO}$ nanopowder in lubricating oil concentration was $0.5 \%$, produced the best antiwear effect.

\section{ACKNOWLEDGEMENTS}

Financial support from Doctoral Fund of University of Jinan is acknowledged.

\section{REFERENCES}

1. Li Weimin, Tribology, 23, 265 (2003)

2. A.H. Battez, R. Gonzoler and D. Felgeoso, Wear, 26, 1568 (2007).

3. J. Xu, W.H. Zhu and J.M. Chen, Tribology, 24, 230 (2004).

4. Y.H. Mo, D.H. Tao and X.C. Wei, Lubrication Eng., 32, 69 (2007).

5. G.C. Jiang, W.C. Guan and Q.X. Zheng, J. Huazhong Univ. Sci. Technol., 31, 98 (2003).

6. Y.L. Qiao, Z.J. Liang and X.F. Sun, J. Tribol., 26, 44 (2006) (in Chinese). 